\section{Warning in time}

Accounts of recent successful earthquake predictions in China have reached Western scientists. Colin Norman reports

Three successful earthquake predictions were made in China last year, and warnings were issued in time to evacuate people from hazardous buildings in the threatened area. But there were also some failures. A number of false alarms were issued, and Chinese scientists failed to predict the devastating earthquake which levelled the city of $T$ 'angshan in July last year.

Those recent successes and failures were discussed for the first time by Chinese scientists who attended an international meeting on earthquake prediction sponsored by UNESCO (the United Nations Educational, Scientific and Cultural Organization) in Paris late last month. According to American scientists who attended the meeting, the Chinese were frank in their discussions and provided much previously unreported information on their methods.

Interest in China's earthquake prediction programme has been intense ever since it became known in the West that Chinese scientists had accurately predicted a major earthquake which struck the city of Haicheng in February 1975. That prediction led to evacution of the city and it is credited with saving many lives.

The latest successful predictions, according to Robert $\mathbf{L}$. Wesson, a seismologist from the US Geological Survey who attended the UNESCO meeting, involved three earthquakes in 1976 of about magnitude 7 on the Richter Scale. They occurred in Yunnan Province on 29 May, in Szechuan Province on 16 August, and in the Szechuan-Yunnan border region on 7 November.

Wesson reported that in each case, Chinese scientists made long-term predictions that an earthquake would occur. Based on a variety of geophysical and magnetic anomalies, the long-term predictions were used as a basis for more intense monitoring in the threatened area, and for disaster planning. They were, however, not made public.

Public warnings that an earthquake was imminent were issued only on the appearance of foreshocks-minor tre- mors which sometimes precede major quakes. The public warnings, according to Wesson, were accompanied by evacuation of people from potentially hazardous buildings. The appearance of foreshocks in the Haicheng area was also used as the trigger for issuing an earthquake warning there in 1975.

Major earthquakes frequently strike abruptly, however, with no foreshocks, and thus imminent hazard warnings may not be issued in time. That seems to have been the case with the T'angshan earthquake. Wesson said that the Chinese had made a medium-term prediction of a quake in the area which had underestimated the magnitude of the event and no imminent warning was issued. In the past, Chinese officials have been reluctant to discuss the T'angshan earthquake, which killed more than 600,000 people.

Wesson also said that the Chinese scientists at the UNESCO meeting admitted that several false alarms have been issued, although their success rate was not revealed. According to Dr Jack Savage, a geophysicist who has visited China, Chinese scientists have acknowledged issuing false alarms before, but they argue that they would prefer to issue warnings whenever necessary rather than risk the consequences of an unpredicted major quake.

\title{
DENMARK
}

\section{Big science in a small country}

A new nuclear physics project is under consideration in Denmark. Sven Godtfredsen reports

THE fate of experimental nuclear physics at Denmark's Niels Bohr Institute is in the process of being decided. An accelerator project now under consideration by the Ministry of Education marks an attempt by the institute to proceed on its own following the failure of an attempt at Scandinavian collaboration. But the enormous costs mean that the matter is likely to become a central issue in Danish science policy.

The project, known as the Danish heavy ion project, was submitted to the Ministry of Education, by the Danish Council for Scientific Policy and Planning. It involves building a $20 \mathrm{MV}$ or $25 \mathrm{MV}$ tandem accelerator. The total cost of the project will include the cost of building the accelerator, estimated at DKr115 million or DKr86 million depending on the choice of terminal voltage, and the DKr3 million increase in grants to the institute for operating the accelerator $\quad(£ 1=\mathrm{DKr} 10.4)$. Financially speaking, the project is breathtaking compared to expenditure on other natural science projects in Denmark. Grants from the Danish Natural Science Research Council (DNSRC) whose function is to finance and to some extent lead Danish research in the natural sciences, amounts to only DKr25 million a year.

The DNSRC gave its view on the project last May in a report called The Future of Nuclear Physics in Denmark. Apart from examining the scientific content of the heavy ion project, the report reviews it in relation to broader issues-specifically, Danish participation in CERN, the attempts to establish collaboration in nuclear physics between the four Scandinavian countries (the NORDAC project), the possibility of collaboration between the institute and the heavy ion laboratory in Darmstadt, and of course, the particular financial aspects of nuclear physics in Denmark. But the question really concerning the DNSRC is how long a small country like Denmark can run its own programme in such an expensive branch of natural science.

This question is not new. It was asked in 1970 when the Niels Bohr Institute needed to renew the $9 \mathrm{MV}$ tandem accelerator, and inspired nuclear physicists from the four Scandinavian countries to discuss the possibility of building a major heavy ion laboratory in the North. The idea was elaborated into the NORDAC project, which the DNSRC strongly recommended and which received financial assurances from the Danish government. Unfortunately the other Scandinavian countries were unable to back the project. Since then the institute has used the heavy ion tandem accelerator in Darmstadt for most of its nuclear physics experiments. But scientists at the institute feel that this approach weakens the contact between experimental and theoretical nuclear physics, traditionally the institute's strong feature.

There is little reason to believe that the NORDAC project is any more likely to happen now, so the Niels Bohr 
Institute has decided to try to proceed on its own. Once again it has obtained full support from the DNSRC which argues that the proposed accelerator must be a national as well as an international asset. Current research at the institute needs an accelerator which provides a beam of very high energy heavy ions with good ionoptic properties and of very precise energy which can be varied rapidly. At present these requirements are only fulfilled by heavy ion tandem accelerators three of which are currently under construction: at Oak Ridge, Tennessee, in the USA (25 MV), at Daresbury in Britain (20 MV, which can be upgraded to $30 \mathrm{MV}$ ) and at the Atomic Energy Research Institute in Japan (20 MV). The DNSRC believes that the kind of nuclear physics research which can be undertaken with these accelerators is so fruitful that more accelerators than these three instruments will be needed in the near future.

Both the DNSRC and the Danish
Council for Scientific Policy and Planning stress that the accelerator is required to continue the close interplay between theoretical and experimental work and "to sustain the status of the Niels Bohr Institute as a centre of excellence". Without the $25 \mathrm{MV}$ or the $20 \mathrm{MV}$ tandem they believe the institute will stagnate; with it they believe the institute will use its capabilities to provide results "with consequences for the world picture presented by modern physics".

\section{COMECON}

- The thirty-second Session of the Comecon Permanent Commission for the Peaceful Uses of Atomic Energy which took place recently in Budapest discussed the long-term draft plan for fuel, energy and raw materials, cooperation in the use of radiation in industry, agriculture and environmental protection, the improvement of anti-radiation precautions and protection, and the disposal of radioactive waste. Also considered was the significance of cooperation in nuclear power for the overall coordinated plan for integrating the member countries' economies. To celebrate the thirtieth anniversary of Comecon, the Commission will publish, in 1979, a book entitled The Peaceful Atom in the Countries of Socialism.

Long-term energy and raw materials needs was also one of the themes of the recent meeting in Havana of the Permanent Commission on Power. In addition to discussing the long-term development of the unified power grids of the continental members of Comecon, special attention was paid to the particular needs of Cuba. A broad programme of new investments includes the construction of the first nuclear power station and the installation of transmission lines of higher tension than the present $220 \mathrm{~V}$. Cuba is already involved in a number of Comecon bilateral agreements for cooperation in nuclear and conventional energy with the USSR, East Germany, Hungary and Poland. According to J. L. Beltrami, the Cuban Minister of the Electrical Industry, it hopes to conclude similar agreemnts with the other member countries in the near future, and to establish a programme of multilateral cooperation.

- A new Comecon international organisation, Agroinform, has been established to coordinate scientific and technical information on agriculture and forestry. It is part of a general policy of integrated information systems for the Comecon bloc, based on the International Scientific and Technical Information Centre of Moscow, to coordinate the

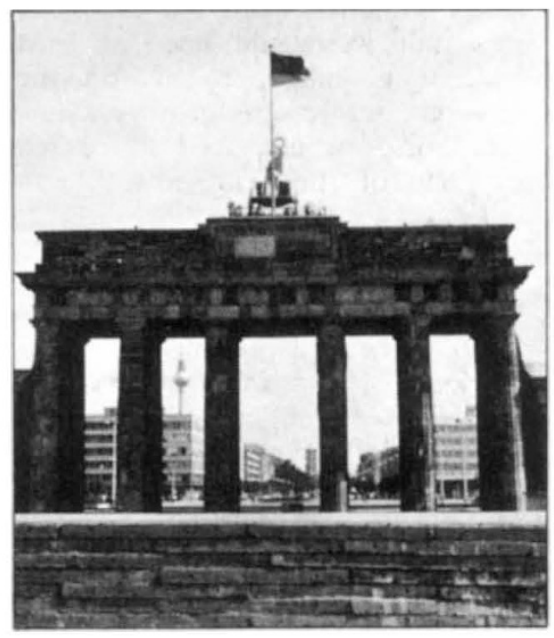

activities of member countries in collecting, selecting and processing information. So far Agroinform has dealt mainly with details of organisation and administration; this autumn, however, its International Council will meet in Prague to discuss the system's technical details. For the present exchange of agricultural information remains largely a matter of bilateral negotiations, such as the recent agreement between the Polish Academy of Sciences and the Czechoslovak Federal Ministry of Agriculture and Food covering research into the genetic and environmental factors affecting the quality of meat.

- During the past few years, Czechoslovak industry has made massive capital investments in plant and machinery purchased from abroad. By the end of 1976, some 15,000 million Czechoslovak crowns had been spent on equipment from 'capitalist' countries, a sum which theoretically is to be recouped by ever-increasing exports. But unfor- tunately, some 58,000 million crowns worth of the imported equipment is still standing idle, due to delay in the construction of factories to house it. At one chemical plant, Chemiceluloza, 200 million crowns worth of imported equipment is reportedly waiting at the construction site and cannot be installed until late in 1978 .

- A second Polish Antarctic research station will come into operation during the coming southern summer. Named the 'Antoni Boleslaw Dobrowolski' station, it was handed over to Poland by the Soviet Union in 1959 but has not been used until now because of a lack of funds. Situated at the Bunger Oasis, $300 \mathrm{~km}$ from the coast and $4,000 \mathrm{~km}$ from the existing Polish 'Henryk Arctowski' station on King George Island, it will conduct mainly geophysical and meteorological research sponsored by the Geophysics Institute of the Polish Academy of Sciences.

The opening of Dobrowolski station is part of a general increase of Polish activity in the Polar regions. After an intensive programme of geophysical, meteorological and oceanographic research at the Arctowski station last summer, a team of 19 scientists manned it for the present winter. Meteorological data from the station forms an important link in the weather-forecasting network based on the Soviet Molodezhnaya station.

- A detailed programme has been worked out for joint Comecon research into the use of solar energy. The programme is largely based on Soviet experience in this field; at present, about 100 small solar power stations are operating in the Soviet Union, and are expected to operate without interruption for more than 10 years. According to the Soviet newspaper Trud, these stations have one great disadvantage-the high cost of the electricity produced.

Vera Rich 